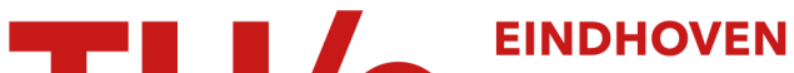 \\ UNIVERSITY OF \\ TECHNOLOGY
}

\section{Study of the electrocrystallization of nickel by ellipsometry}

\author{
Citation for published version (APA): \\ Abyaneh, M. Y., Visscher, W., \& Barendrecht, E. (1983). Study of the electrocrystallization of nickel by \\ ellipsometry. Electrochimica Acta, 28(3), 285-291. https://doi.org/10.1016/0013-4686(83)85124-X
}

DOI:

10.1016/0013-4686(83)85124-X

Document status and date:

Published: 01/01/1983

\section{Document Version:}

Publisher's PDF, also known as Version of Record (includes final page, issue and volume numbers)

\section{Please check the document version of this publication:}

- A submitted manuscript is the version of the article upon submission and before peer-review. There can be important differences between the submitted version and the official published version of record. People interested in the research are advised to contact the author for the final version of the publication, or visit the $\mathrm{DOI}$ to the publisher's website.

- The final author version and the galley proof are versions of the publication after peer review.

- The final published version features the final layout of the paper including the volume, issue and page numbers.

Link to publication

\section{General rights}

Copyright and moral rights for the publications made accessible in the public portal are retained by the authors and/or other copyright owners and it is a condition of accessing publications that users recognise and abide by the legal requirements associated with these rights.

- Users may download and print one copy of any publication from the public portal for the purpose of private study or research.

- You may not further distribute the material or use it for any profit-making activity or commercial gain

- You may freely distribute the URL identifying the publication in the public portal.

If the publication is distributed under the terms of Article 25fa of the Dutch Copyright Act, indicated by the "Taverne" license above, please follow below link for the End User Agreement:

www.tue.nl/taverne

Take down policy

If you believe that this document breaches copyright please contact us at:

openaccess@tue.nl

providing details and we will investigate your claim. 


\title{
STUDY OF THE ELECTROCRYSTALLIZATION OF NICKEL BY ELLIPSOMETRY
}

\author{
M. Y. Abyaneh, W. Visscher and E. Barendrecht
}

\begin{abstract}
Laboratory for Electrochemistry, Department of Chemical Technology, Eindhoven University of Technology, P. O. Box 513, 5600 MB Eindhoven, The Netherlands
\end{abstract}

(Received 2 August 1982)

\begin{abstract}
A bstract - The initial stages of the electrocrystallization of nickel are studied by simultaneous ellipsometric and amperometric investigation during potentiostatic deposition. Theorelical eyuatiuns for $\Delta$ and $\Psi$-time transients are derived for both conical and hemispherical growth forms. It is shown that these equations can adequately describe the experimental optical transient data. Moreover, the ellipsometric monitoring of the deposition process gives information regarding the topography of the deposit.
\end{abstract}

\section{INTRODUCTION}

The study of electrocrystallization processes is both of theoretical and practical interest. The kinetics and the morphology of the deposit have been shown to be determined by the very initial stages. These initial steps can be adequately studied by the potential step technique. Detailed models of nucleation and crystal growth have been developed and theoretical current-time relationships have been derived[1]. Experimental transients of the electrocrystallization of nickel were studied by computer aided analysis[2].

Ellipsometry is an optical method for in situ monitoring of film growth on a substrate. It will be shown in this paper that simultaneous ellipsometric and amperometric investigation during the potentiostatic deposition will provide further information about electrocrystallization.

Ellipsometry is the measurement of the state of polarization of light[3]. It is used to determine either the properties of a surface or the properties of a film on a known substrate. The technique is based on the relative changes in the polarization state of light occurring during reflection at a substrate and has been shown to be a sensitive method for detection of very thin films.

The measured parameters $\Delta$ (phase difference) and $\Psi$ (arctan of amplitude ratio) are related to the optical constants by the expression

$$
\begin{aligned}
& \rho=\tan \Psi \mathrm{e}^{\mathrm{i} \Delta}, \\
& \rho=\text { complex reflection coefficient. }
\end{aligned}
$$

For a three-phase system (medium-film-substrate) $\rho$ is a function of the refractive index of the medium $\left(N_{\mathrm{M}}\right)$, film $\left(N_{\mathrm{F}}\right)$ and substrate $\left(N_{\mathrm{S}}\right)$; as well as of the angle of incidence $(\phi)$, wavelength $(\lambda)$ and film thickness $(d)$. In formula

$$
\begin{aligned}
\rho= & \frac{r_{\mathrm{MF}, \mathrm{p}}+r_{\mathrm{FS}, \mathrm{p}} \exp (-\mathrm{i} D)}{1+r_{\mathrm{MF}, \mathrm{p}} r_{\mathrm{FS}, \mathrm{p}} \exp (-\mathrm{i} D)} \\
& \times \frac{1+r_{\mathrm{MF}, \mathrm{s}} r_{\mathrm{FS}, \mathrm{s}} \exp (-\mathrm{i} D)}{r_{\mathrm{MF}, \mathrm{s}}+r_{\mathrm{FS}, \mathrm{s}} \exp (-\mathrm{i} D)}
\end{aligned}
$$

with

$$
D=4 \pi(d / \lambda) N_{\mathrm{F}} \cos \phi_{\mathrm{F}} \quad \text { (Fig. 1); } \quad r_{\mathrm{MF}}, \quad r_{\mathrm{FS}}
$$

$=$ Fresnel coefficient of reflection at boundary between 2 phases $M-F$, respectively $F-S$; subscripts $p$ and $s$ refer to parallel and perpendicular light.

For an ideal isotropic film, calculation of $\Delta$ and $\Psi$ for a known value of $N_{\mathrm{F}}$ is a straightforward procedure. Vice versa, $N_{F}$ and $d$ can be obtained from measured values of $\Delta$ and $\Psi$.

When this 3-phase model is applied to study film growth, it requires that film formation should occur via initial rapid formation of a thin homogeneous film which subsequently grows homogeneously into the solution. However, such a growth model is not realistic for electrocrystallization processes and therefore a model will be developed to calculate $\Delta$ and $\Psi$ during film growth on a substrate.

\section{THEORETICAL}

Electrocrystallization processes usually take place via nucleation and three-dimensional growth of centres[4, 2]. The deposit (at least during the initial stages of growth) is, therefore, rough and its topography is continuously changing with time. This implies that the three phase model, Fig. 1, is not applicable for these processes as there is no smooth boundary parallel to the substrate between the deposit and the medium. Here we propose a model, Fig. 2 , in which the film phase of Fig. 1 is substituted by a layer, of thickness $d$, consisting of the deposit and the medium and having a

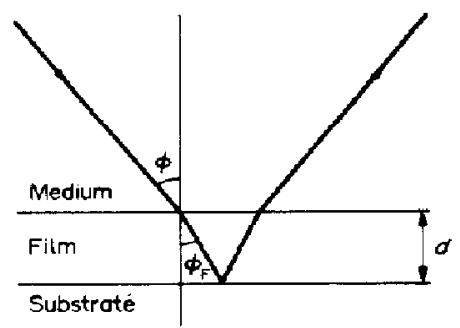

Fig. 1. Reflection of light at a substrate covered with film of thickness $d$. 


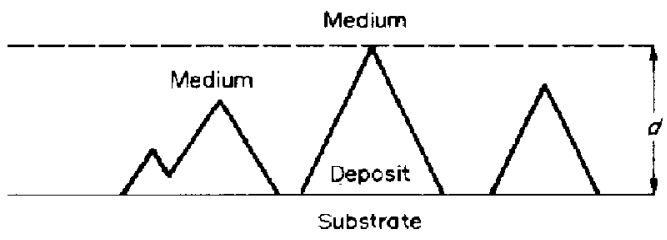

Fig. 2. Film layer model used for the calculation of $\boldsymbol{N}_{\mathrm{eff}}$.

time-dependent refractive index, $N_{\text {eff. }}$ It is assumed that, $N_{\text {efri, }}$ at any time $t$ follows the simple relationship

$$
N_{\text {eff }}=\omega N_{\mathrm{D}}+(1-\omega) N_{\mathrm{M}} \text {, }
$$

where $\omega$ is the volume fraction of the deposit and is given by

$$
\omega=\frac{V}{d} .
$$

$N_{\mathrm{D}}=$ refractive index of the deposited metal; $V$ is the actual volume of the deposit per unit area of the substrate.

Now $V$ is related to the current density $i$ :

$$
V=\frac{M}{z F \rho} \int_{0}^{1} i_{v} \mathrm{~d} v
$$

where $M\left(\mathrm{~g} \mathrm{~mol}^{-1}\right)$ and $\rho\left(\mathrm{g} \mathrm{cm}^{-3}\right)$ are the molecular weight and the density of the deposit and $z F\left(\mathrm{C} \mathrm{mol}^{-1}\right)$ is the charge transferred per deposited ion. The current $i$, at any time $v$ and therefore $N_{\text {eff }}$ depends on the shape of growth centres. Several forms of growth can be considered. Here two forms are given.

\section{Right-circular cone growth forms}

Figure 3 depicts the growth forms at different times. The general current-time equation due to the poten-

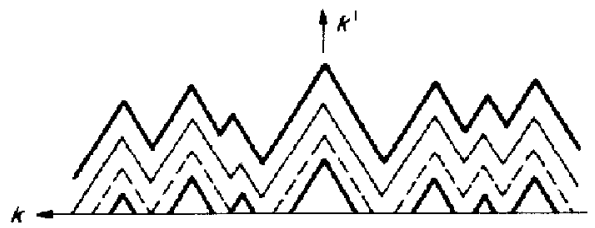

Fig. 3. Growth of right-circular cones, shown at four different times.

tiostatic deposition is given by [5]

$$
\begin{aligned}
i_{v}= & z F k^{\prime}\left(1-\exp \left\{\frac{-\pi M^{2} k^{2} A}{A^{\prime} p^{2}}\right.\right. \\
& \left.\left.\times\left[v^{2}-\frac{2 v}{A^{\prime}}+\frac{2}{A^{\prime 2}}-\frac{2}{A^{\prime 2}} \exp \left(-A^{\prime} v\right)\right]\right\}\right)
\end{aligned}
$$

where $k^{\prime}\left(\mathrm{mol} \mathrm{cm} \mathrm{cm}^{-2} \mathrm{~s}^{-1}\right)$ and $k\left(\mathrm{~mol} \mathrm{~cm}{ }^{-2} \mathrm{~s}^{-1}\right)$ are the rates of crystal growth in the direction, respectively, perpendicular and parallel to the substrate, $A$ (nuclei $\mathrm{cm}^{-2} \mathrm{~s}^{-1}$ ) is the original rate of nucleation per unit area of the substrate and $A^{\prime}\left(\mathrm{s}^{-1}\right)$ is the rate of conversion of a site into a nucleus. It has been shown[2] that for the deposition of nickel from sulphate media the initial rising current can be ad- equately described by the equation[4]

$$
i=z F k^{\prime}\left[1-\exp \left(\frac{-\pi M^{2} k^{2} A v^{3}}{3 \rho^{2}}\right)\right]
$$

which follows from $(6)$ for the special case: $\left(1 / A^{\prime}\right)$ large compared to the overall transient time.

Equations (6) and (7) predict an asymptotic approach of the current to a value of $z F k^{\prime}\left(\mathrm{A} \mathrm{cm}^{-2}\right)$ at long times, as is shown in Fig. 4. The experimental transient current due to the electrocrystallization of nickel, however, goes through a maximum[2]. This maximum current was then explained by introducing a "death" and "rebirth" mechanism $[1,2]$ in which cessation of crystal growth ("death") in the direction perpendicular to the substrate and synchronized renucleation ("rebirth") of new centres is assumed to take place. It must be noted that (7) can still be used for the initial stages prior to "death" and "rebirth" of growth centres.

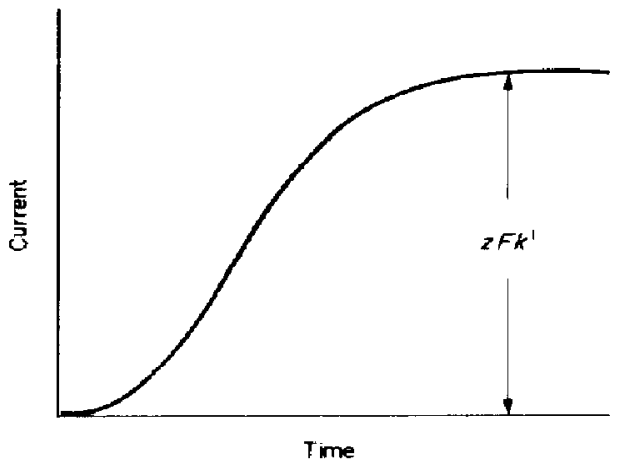

Fig. 4. Current-time transient for potentiostatic deposition according to (6) and (7).

The actual volume fraction, $\omega$, at any time $t$ prior to "death" and "rebirth", is given by the combination of (4), (5) and (7) with

$$
d=\frac{M k^{\prime}}{\rho} t
$$

therefore,

$$
\omega=1-\frac{1}{t} \int_{0}^{t} e^{-P v^{3}} \cdot d v
$$

where

$$
P=\frac{\pi M^{2} k^{2} A}{3 \rho^{2}} .
$$

The value of $N_{\text {eff }}$ at any time $t$ is then obtained by substituting equation (9) into (3).

\section{Hemispherical growth forms}

A second growth form which will be considered, is growth via hemispherical centres (Fig. 5). It was recently shown[6] that nucleation and threedimensional growth of hemispherical centres can account for the whole current-time transients due to the electrocrystallization of nickel without the concept of "death" and "rebirth". The current-time equation 


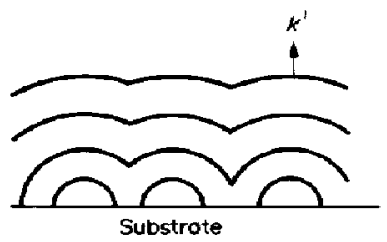

Fig. 5. Growth of hemispherical centres shown at four different times.

for (1/A ) large compared to the time $v$ (as in the case of deposition of nickel from sulphate media), is given by $[6]$

$$
\begin{aligned}
i= & 3 z F k P \int_{0}^{v}\left(v^{2}-u^{2}\right) \\
& \times \exp \left[-P\left(v^{3}-3 v u^{2}+2 u^{3}\right)\right] \mathrm{d} u,
\end{aligned}
$$

where $k\left(\mathrm{~mol} \mathrm{~cm}^{-2} \mathrm{~s}^{-1}\right)$ is the rate of growth of hemispherical centres. The volume fraction is then given by the combination of (4), (5) and (11) with

$$
d=\frac{M k}{\rho} t
$$

Therefore,

$$
\begin{aligned}
\omega= & \frac{3 P}{t} \int_{0}^{t} \int_{0}^{v}\left(v^{2}-u^{2}\right) \\
& \times \exp \left[-P\left(v^{3}-3 v u^{2}+2 u^{3}\right)\right] \mathrm{d} u \mathrm{~d} v .
\end{aligned}
$$

By substituting (13) in (3) $N_{\text {eff }}$ based on the hemispherical growth form is obtained.

With $N_{\text {eff }}$ and $d$ calculated for the two growth forms, $\Delta$ and $\Psi^{\prime}$ transients can now be computcd using (1) and (2).

\section{EXPERIMENTAL}

1 he electrodeposition experiments were carried out for $\mathrm{Ni}$ and $\mathrm{Co}$ deposition on vitreous carbon substrate. The subsirate was embedded in perspex and arranged in an electrode holder. The optical cell was a cylindrical Teflon cell with quartz windows fixed for angle of incidence of $70^{\circ}$.

The experiments were performed using a saturated calomel electrode as the reference electrode and $\mathrm{Pt}$ as the counter electrode. The solutions were prepared using Anala R chemicals.

The ellipsometer was the Rudolph RR 2000 automatic with $546.1 \mathrm{~nm}$ filter for the $\mathrm{Ni}$ deposition experiments and with a $650 \mathrm{~nm}$ filter for the Co experiments.

Potential steps were applied with a WENKING potentiostat controlled by a PAR Model 175 Universal programmer.

The changes in current, $\Delta$ and $\Psi$ during the application of a potential step were simultaneously recorded.

\section{Preparation of the substrate}

The vitreous carbon (area $0.20 \mathrm{~cm}^{2}$ ) electrode was mechanically polished with successively finer grades of alumina, down to $0.05 \mu \mathrm{m}$, the electrode was then cleaned ultrasonically in double distilled water.

\section{RESULTS}

$\mathrm{Ni}$ electrodeposition was carried out from $0.1 \mathrm{M}$ $\mathrm{NiSO}_{4}+0.6 \mathrm{M} \mathrm{NaCl}+0.58 \mathrm{M} \mathrm{H}_{3} \mathrm{BO}_{3}$.

After insertion of the sample, the $\Delta$ and $\Psi$ readings were taken at the initial potential of $-120 \mathrm{mV}$ es sce; then a potentiostatic step to $E=-900 \mathrm{mV}$ was applied. The transients for current, $\Delta$ and $\Psi$ are given in Figs 6 and 7 , respectively

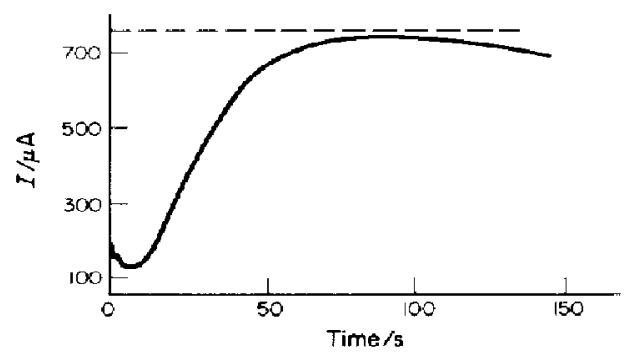

Fig. 6. Current-time transient due to the electrodeposition of nickel on a vitreous carbon substrate during a potential step from $E=-120$ to $E=-900 \mathrm{mV}$ (vs sce). Solution composition $0.1 \mathrm{M} \mathrm{NiSO}_{4}, 0.6 \mathrm{M} \mathrm{NaCl}$ and $0.58 \mathrm{M} \mathrm{H}_{3} \mathrm{BO}_{3}$.

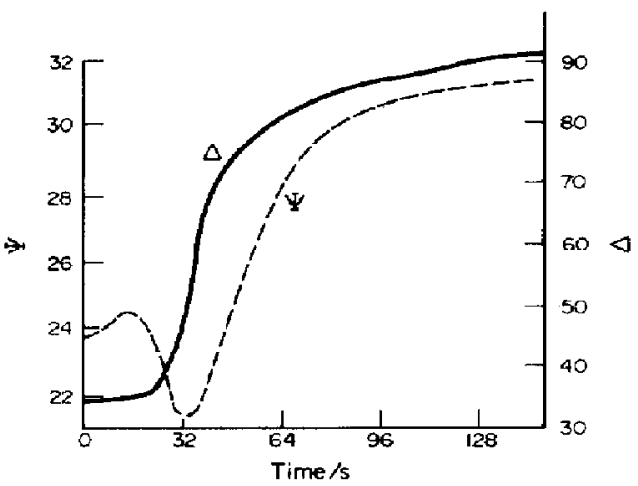

Fig. 7. As in Fig. 6, ellipsometric $\Delta$ and $\Psi$ transient.

Co electrodeposition was carried out from $0.1 \mathrm{M}$ $\mathrm{CoSO}_{4}+0.58 \mathrm{M} \mathrm{H}_{3} \mathrm{BO}_{3}$ by applying a potential step from the open circuit potential $E_{\text {oc }}=17 \mathrm{mV}$ to $E=$ $-925 \mathrm{mV}$ vs sce. The results are given in Fig. 8.

\section{DISCUSSION}

\section{S.1 Nickel-deposition}

In the theoretical section equations were derived by which the shape of the $\Delta-t$ and $\Psi-t$ transients can be computed provided that the parameter $\boldsymbol{P}$ [defined in (10)] and the refractive indices of deposited metal, substrate and medium are known.

For the model based on the conical growth form, $P$ is obtained from the maximum slope of the rising part of the current-time transient according to 


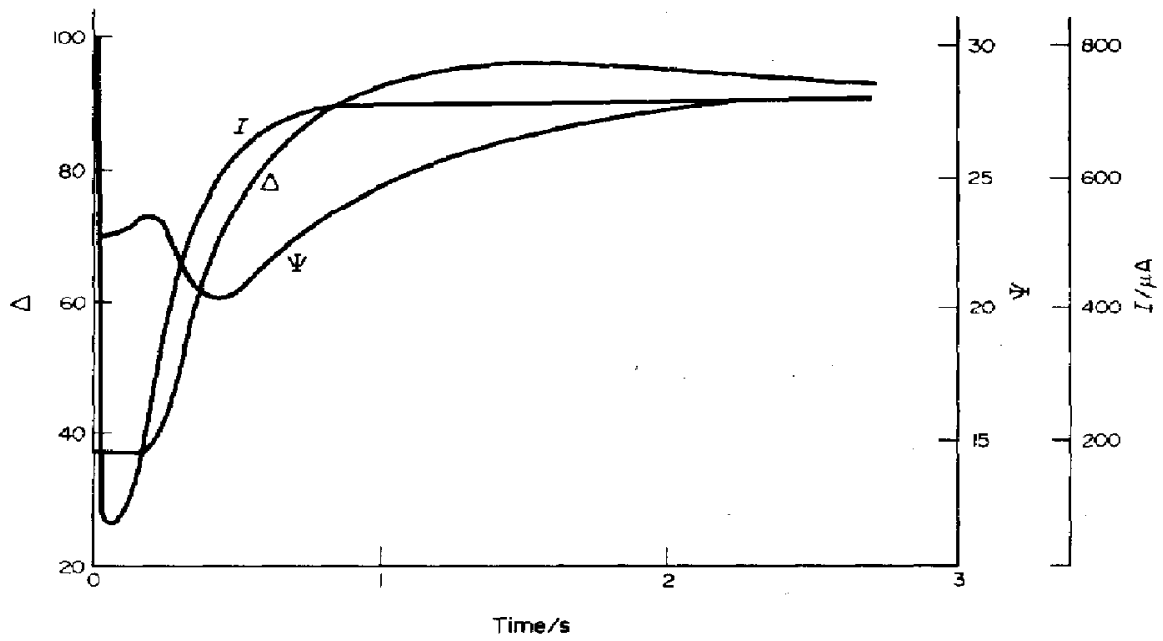

Fig. 8. Current, $\Delta$ and $\Psi$ transients of the electrodeposition of cobalt on a vitreous carbon electrode during a potential step from $E=17$ to $-925 \mathrm{mV}$ us sce.

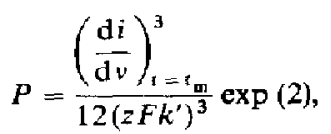

$(\mathrm{d} i / \mathrm{d} v)_{\mathrm{r}}=\mathrm{t}_{\mathrm{m}}$ is the differential of (7) at time $t_{\mathrm{m}}$ where the differential has a maximum value.

The value of $z F k^{\prime}$ is obtained from the maximum current. From the experimental current-time transient for nickel (Fig. 6) a value of $P=1.7 \times 10^{-5} \mathrm{~s}^{-3}$ and a growth rate of $9 \mathrm{As}^{-1}$ is obtained. Using these data and with $N_{\mathrm{D}}=2.0-4.0 i$, the $\Delta-t$ and $\Psi$ - $t$ transients are computed (Fig. 9). The calculated $\Delta-t$ transient follows nearly the same pattern as observed experimentally (fig. 7) except for the initial shallow minimum. The calculated $\Psi-t$ transient, however, though it shows a maximum and a minimum as observed experimentally (Fig. 7) differs both in the time and in the value at which the predicted maximum and minimum are observed.

It was found that decreasing the value of the rate of outward growth (v) would change $\Psi_{\max }$ and $\Psi_{\min }$

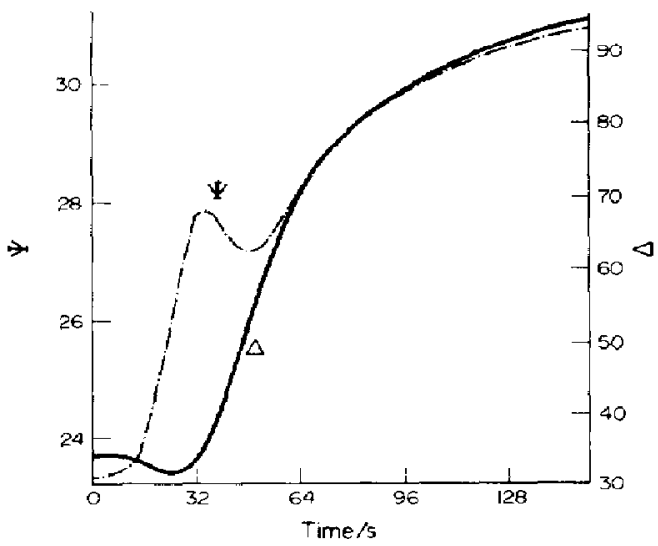

Fig. 9. Calculated $\Delta, \Psi$ transient for conical growth form with $P=1.7 \times 10^{-5} \mathrm{~s}^{-1}$; growth rate $=9 \mathrm{~A} \mathrm{~s}^{-1} ; N_{\mathrm{D}}=2-4 \mathrm{i}$. towards the experimental data as can be seen in Fig. 10. However, a lower v-value cannot be accounted for in the conical model; the value of $v$ will even be larger if "death" and "rebirth" of crystal growth are taken into consideration. We also note that even an unrealistic assumption of $2 \mathrm{As}^{-1}$ for the rate of outward growth of cones does not predict the correct time at which a maximum and a minimum in $\Psi$ is obtained (compare Fig. 10 b with Fig. 7).

The hemispherical growth model, however, predicts smaller values of growth rate. Figure 11 shows the $\Delta-t$ and $\Psi-t$ transients calculated with the hemispherical model, with $N_{D}=2.0-4.0 i$ and for a growth rate of $3 \mathrm{As}^{-1}$, which gives the best fit with the experimental results of Fig. ?.

Obviously the hemispherical model not only explains the current-time transient without any further assumptions as was necessary for the conical model,

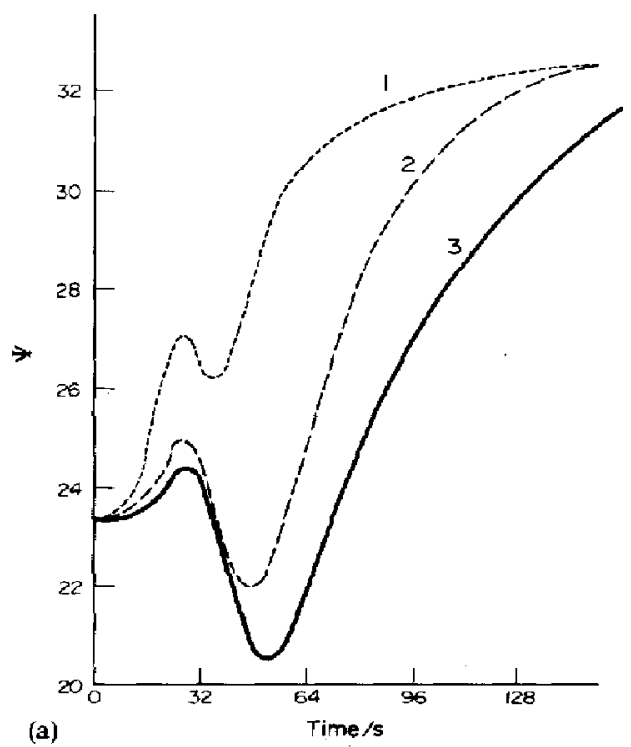




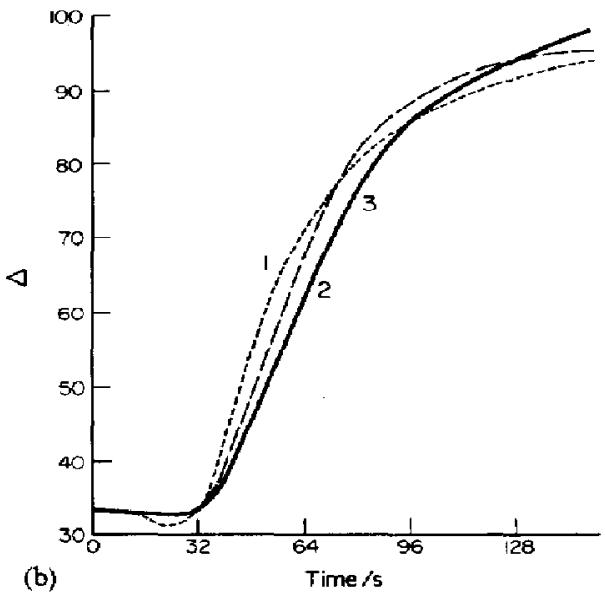

Fig. 10. a, b. Calculated $\Delta$ (a) and $\Psi$ (b) transients for conical growth form with $P=1.7 \times 10^{-5} \mathrm{~s}^{-1} ; N_{\mathrm{D}}=2-4 i$ and growth rates of $9 \mathrm{As}^{-1}$ (curve 1), $3 \mathrm{As}^{-1}$ (curve 2) and $2 \mathrm{As}^{-1}$ (curve 3).

but it also approaches the experimental curve more sensibly. The above found value of $3 \mathrm{As}^{-1}$ is too low [6], however, that is to say a more rapid increase with time of the volume fraction is required; consideration of other growth forms will be given in future publications.

A higher volume fraction indicates a higher effective optical density of the layer which can also be effected by a higher value of $N_{\mathrm{D}}$. The value of the refractive index of the deposited nickel under the above experimental conditions is not exactly known. Figure $12 \mathrm{a}, \mathrm{b}$ shows the effect of a change of $N_{D}$ on the optical transients. The value of $N_{\mathrm{D}}=2-4 i$ as used in the calculation of Fig. 11 was found to give the best fit. This value is in reasonable agreement with literature data.

Increase of the rate of coverage $(P$ ) has, of course, a similar effect. Increase of $P$ shifts the $\Delta-t$ and $\Psi-t$ transients to shorter times, as shown in Fig. 13.

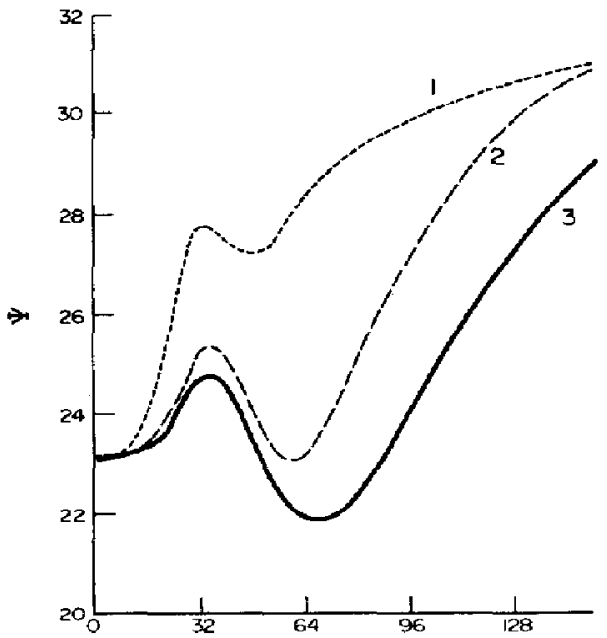

(a)

Timers

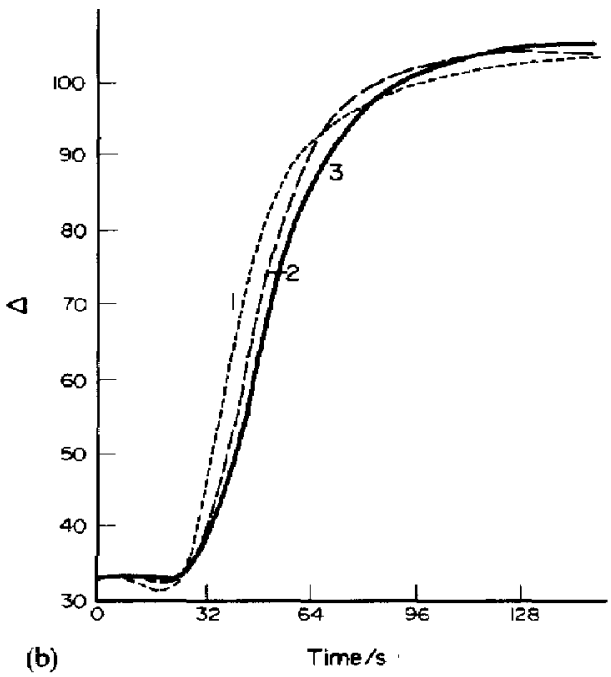

Fig. 11. a, b. Calculated $\Delta$ (a) and $\Psi$ (b) transients for hemispherical model with $P=1.7 \times 10^{-5} \mathrm{~s}^{-1} ; N_{\mathrm{D}}=2-4 i$ and growth rates of $9 \mathrm{As}^{-1}$ (curve 1), $3 \mathrm{As}^{-1}$ (curve 2) and $2 \mathrm{As}^{-1}$ (curve 3).

\subsection{Cobalt deposition}

The observed current-time transient of the deposition of cobalt, Fig. 8, has the same shape as that of nickel. Therefore, the optical transients can be expeeted to be similar to those of nickel, as was indecd observed (Fig. 8).

\subsection{The model}

The model used for the calculation of the film refractive index is based on the addition rule. Such a rule has been applied by Archer[7] for submonolayer coverage and it has been shown in several cases that for very thin films the experimental results permit the application of this model. Other models have also been

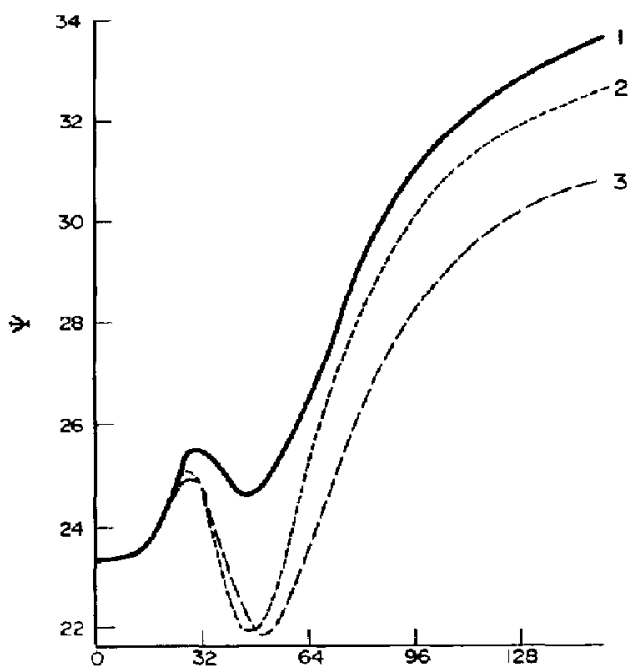

(a)

Time/s 


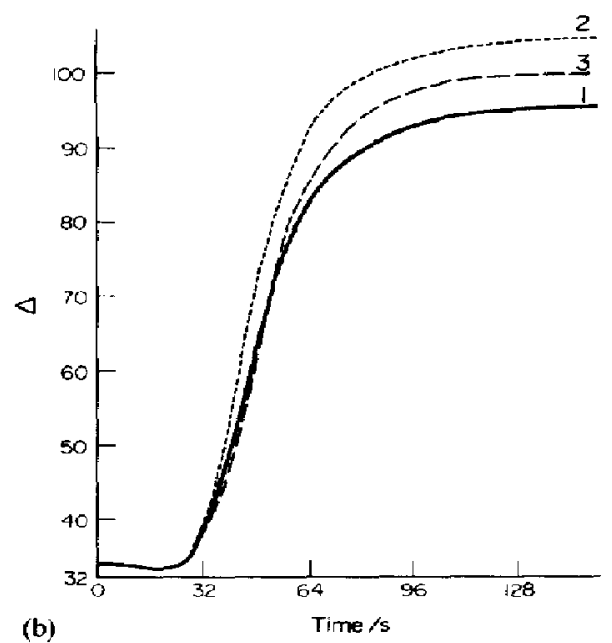

Fig. 12. a, b. Effect of change of $N_{D}$ values on the calculated $\Delta(a)$ and $\Psi$ (b) transients (hemispherical model) with $P=1.7$ $\times 10^{-5} \mathrm{~s}^{-1}$ and growth rate $3 \mathrm{~A} \mathrm{~s}^{-1} ; N_{\mathrm{D}}=1.5-3.5 i$ (1); $N_{\mathrm{D}}$ $=2-4.0 i(2) ; N_{\mathrm{D}}=2-3.5 i(3)$.
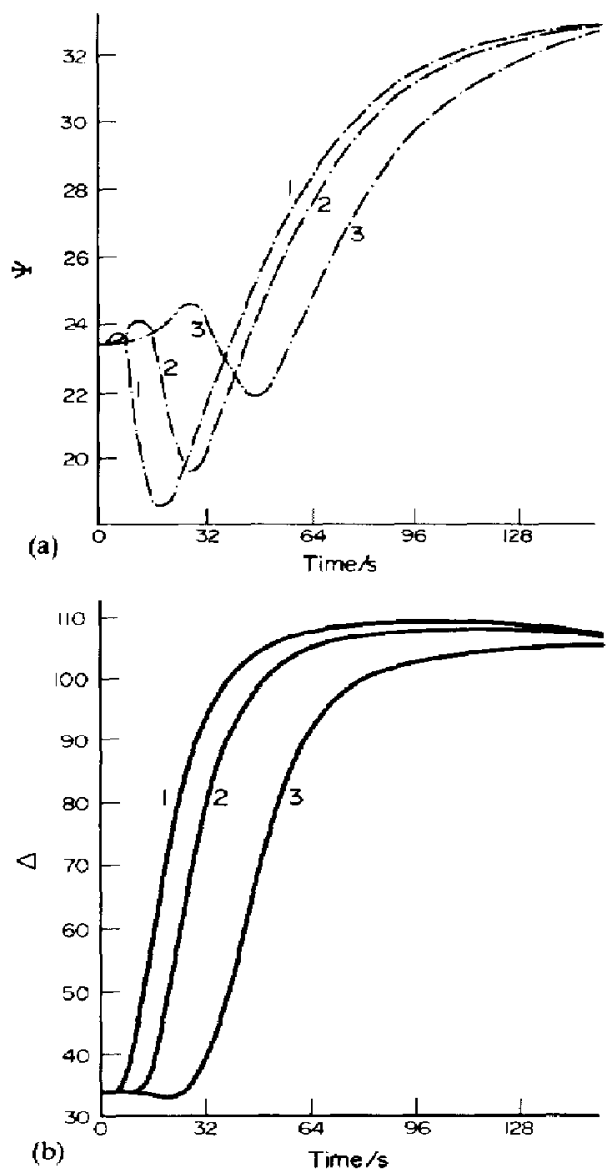

Fig. 13. a, b. Effect of increase of the rate of coverage $(P)$ on the calculated $\Delta$ (a) and $\Psi$ (b) transients (hemispherical model) with $N_{\mathrm{D}}=2-4 i$, growth rate $3 \mathrm{As}^{-1} ; P=1.7 \times 10^{-3} \mathrm{~s}^{-1}(1)$; $1.7 \times 10^{-4} \mathrm{~s}^{-1}(2) ; 1.7 \times 10^{-5} \mathrm{~s}^{-1}(3)$ proposed for the calculation of an effective refractive index such as that based on the Maxwell Garnett theory [3].

This theory can only be applied if the film consists of particles randomly distributed. The application of such a model to electrocrystallization obviously fails; although centres of growth are randomly formed on the substrate, they are not randomly distributed in the film.

Hence, the model proposed was used to get some idea about the shape of the $\Delta, \Psi$ transients. The above results show that the $\Delta, \Psi$ transients calculated on the basis of this model are in agreement with the experimental transients. The change in $N_{\text {eff }}$ with time as calculated for the case of Fig. 11 with growth rate of $3 \mathrm{As}^{-1}$ is given in Fig. 14. The value of $n-i k$ after $150 \mathrm{~s}$ is $1.95-3.72 i$ which implies that $\omega$ at this time is about $90 \%$.

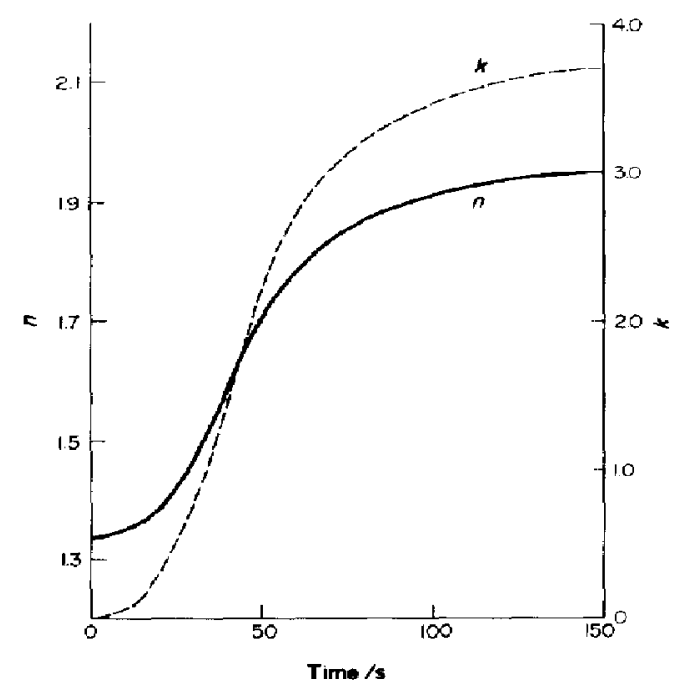

Fig. 14. Change $N_{\text {eff }}$ with time during film growth, calculated with data of Fig. 11, $v=3 \mathrm{As}^{-1}$ (curve 2).

\section{CONCLUSIONS}

Theoretical equations were derived for the variation of $\Delta$ and $\Psi$ with time during an electrocrystallization process. Despite the complexity of the formulae, these questions can adequately describe the optical transient data.

Furthermore, the ellipsometric monitoring of the deposit seems to be also a transient technique which can distinguish the detailed shape (topography) of the growth centres. This was shown by comparing the experimental optical data for the deposition of nickel with the calculated optical transients for the two growth forms: right-circular cone and hemispherical.

The dominating factor in the determination of the shape of the $\Delta$ and $\Psi$ transients is shown to be the optical density of the composite layer which in turn is determined by the volume fraction and the refractive index of the deposited metal. 
Acknowledgement-One of us (M.Y.A.) would like to thank the Netherlands Organization for the Advancement of Pure Research (Z.W.O.), the NIVEE-Foundation and the Eindhoven University of Technology for the fellowship.

\section{REFERENCES}

1. M. Y. Abyaneh and M. Fleischmann, J.electroanal. Chem 119, $187(1981)$.
2. Ibid., 119, 197 (1981).

3. R. M. A. Azzam and N. M. Bashara, Ellipsometry and Polarized Light. North-Holland, London (1977).

4. R. D. Armstrong, M. Fleischmann and H. R. Thirsk, $J$. electroanal. Chem. 11, 208 (1966).

5. M. Y. Abyaneh and M. Fleischmann, Electrochim. Acta 27, 1513 (1982).

6. M. Y. Abyaneh, Electrochim. Acta, 27, 1329 (1982).

7. R. J. Archer, in Ellipsometry in the Measurement of Surfaces and Thin Films (Edited by E. Passaglia et al.) p. 255. N.B.S. Mise. Publ. 256, Washington D.C. (1964). 